\title{
Duchenne muscular dystrophy
}

INSERM

\section{Source}

INSERM. (1999). Orphanet: an online rare disease and orphan drug data base. Duchenne muscular dystrophy. ORPHA:98896

Duchenne muscular dystrophy (DMD) is a neuromuscular disease characterized by rapidly progressive muscle weakness and wasting due to degeneration of skeletal, smooth and cardiac muscle. 